\title{
ELECTROCARDIOGRAPHIC STUDIES IN PATIENTS WITH AN ARTIFICIAL PACEMAKER
}

\author{
BY
BENGT W. JOHANSSON, JOHAN KARNELL, ARNE MALM, JAN SIEVERS, AND JÖRGEN SWEDBERG From the Cardiological Laboratory, Department of Medicine, and Department of Thoracic Surgery, Allmänna Sjukhuset,
Malmö, Sweden

Received December 27, 1962

The interest in Adams-Stokes syndrome has greatly increased since the development of effective treatment by artificial electrical stimulation of the heart and the appearance of methods for closedchest defibrillation. A review of the published work and a report of our material in Malmö has been published earlier (Johansson, 1961). A major development in the treatment of Adams-Stokes syndrome has been the development of closed-chest cardiac massage. We have employed this method satisfactorily with about 70 patients and published the preliminary reports elsewhere (Johansson, 1962; Johansson et al., 1962).

The treatment of Adams-Stokes syndrome by an artificial pacemaker with electrodes placed directly on the myocardium has become an accepted procedure. Some of the reports have been reviewed earlier (Johansson, 1961) and more have appeared since (Chardack, Gage, and Greatbatch, 1960 and 1961; Escher et al., 1961; Holswade and Linardos, 1961; J. Landegren, 1961, personal communication; Meier-Sydow et al., 1961; Müller and Bellet, 1961; Zoll et al., 1961; Castberg, Jarlov, and Rasmussen, 1962; Dittmar, Friese, and Holder, 1962). We now have 9 patients who are using artificial pacemakers.

Two types of pacemaker have been used, one described by Chardack et al. (1960 and 1961) and one developed by Elmqvist (Johansson, 1961). The Chardack type (Fig. 1) (manufactured by Medtronics, Inc., Minneapolis, Minn.) is a transistorized and subcutaneously implantable pacemaker encapsulated in a double shell of silicone rubber. The pacemaker delivers a biphasic $2 \mathrm{msec}$. pulse at a preset rate of 60 a minute. In this pacemaker type it is possible to change the stimulus rate and the amplitude. However, in our experience, this is a complicated and impractical procedure when the pacemaker is implanted. Power is supplied from 10 mercury cells and the circuit has been designed to deliver $10 \mathrm{~mA}$ against an impedance of $1000 \mathrm{ohms}$. The bipolar electrode is a helical coil spring made from platinum-iridium alloy wire insulated by silicone rubber. The Elema type (Elmquist) (Fig. 2) (manufactured by Elema-Schönander, Stockholm-Solna, Sweden) is also a transistorized and subcutaneously implantable pacemaker encapsulated in epoxy resin. It has two screw connexions for the electrode wires which are made of flexible fatigue-resistant stainless steel, insulated by polyethylene. The two lot myocardial electrodes are made of pure platinum each with a diameter of $9 \mathrm{~mm}$. and covered with epoxy resin. Each electrode is provided with two holes for suturing. The pulse generator contains a long-life mercury battery and delivers six volts against an impedance of $300 \mathrm{ohms}$. The impulse duration is $2.5 \mathrm{msec}$. and the rate is set at 72 a minute.

\section{CASE REPORTS}

Case 1. Born 1916. In 1952 a systolic murmur was noted over the base of the heart and was attributed to aortic stenosis. In October 1960 he had his first attack of unconsciousness with tonic cramps. The 


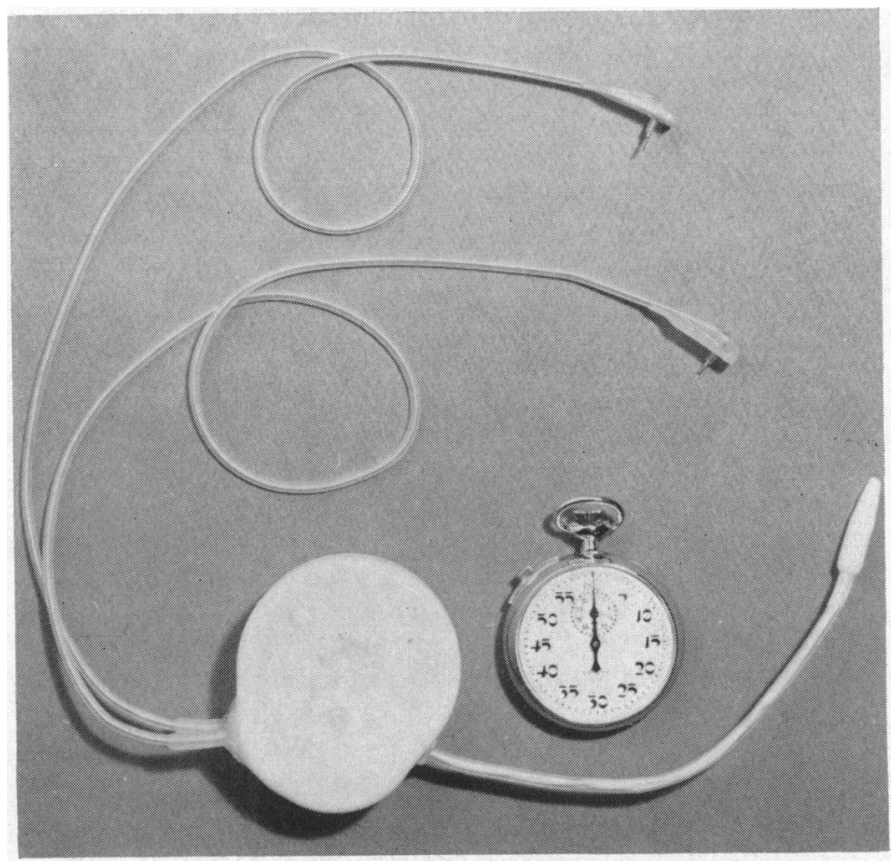

FIG. 1.-Chardack pacemaker.

electrocardiogram showed complete heart block and sinus rhythm. Radiography of the heart and lungs was normal. The blood pressure was $115 / 65 \mathrm{~mm}$. $\mathrm{Hg}$. Laboratory examinations gave normal results except for slight leucocytosis and a cholesterol value of 400 $\mathrm{mg} . / 100 \mathrm{ml}$. He was given ephedrine, atropine, and ACTH without effect, but after prednisolone treatment his attacks disappeared and his cardiogram then showed sinus rhythm.

After a short period of freedom his attacks recurred and an electrocardiogram taken during an attack showed asystole. ACTH and steroid treatment sometimes decreased the frequency of attacks but isoprenaline was the more consistently effective agent. In 1961, after a series of attacks increasing both in frequency and severity, culminating in profound unconsciousness, cyanosis, and cramps, it was decided to implant an Elema artificial pacemaker. Since this operation he has felt well. One and a half years after operation he has returned to work and has had no further attacks of unconsciousness.

Case 2. Born 1887. Cholecystolithiasis was diagnosed in 1956. In March 1961 repeated Adams-Stokes attacks appeared, which seemed to be connected with her gall-stone attacks (Johansson, 1960). After a couple of days she improved. In December 1961 AdamsStokes attacks and cholecystitis again appeared. The electrocardiogram during an attack showed initially ventricular fibrillation followed by asystole. Her gall-

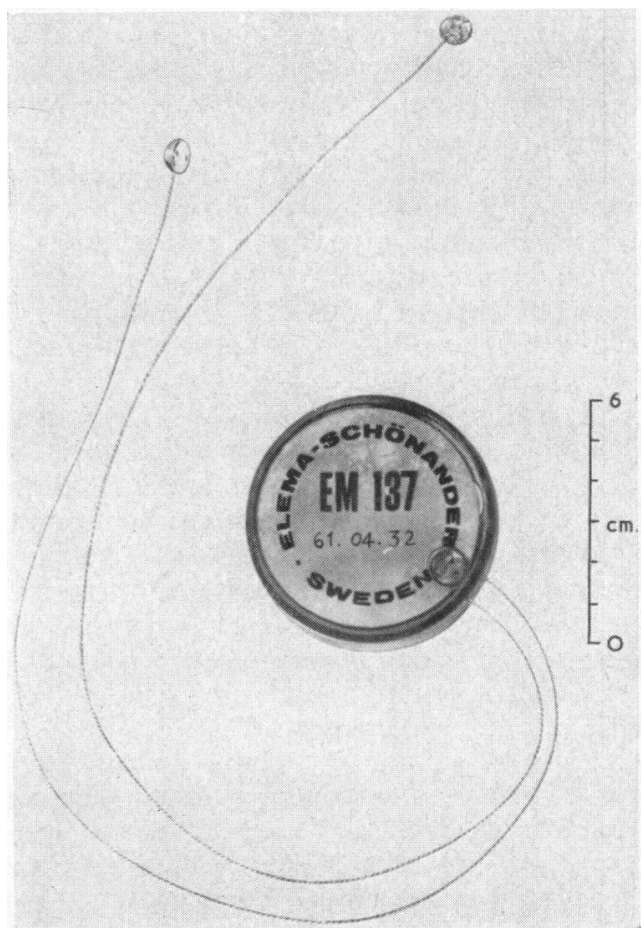

Fig. 2.-Elema pacemaker. 
bladder was removed uneventfully and found to contain many small stones. It is of interest that at operation when the pressure in the gall-bladder was increased by injection of saline there was no asystole but multiple ventricular extrasystoles appeared. The extrasystoles were very irregular, almost resembling ventricular fibrillation. The cardiogram showed complete heart block which had been known since March 1961. In March 1962 new Adams-Stokes attacks appeared and an artificial pacemaker (Chardack type) was implanted. After this operation, which was uneventful, she has felt well and has had no AdamsStokes attacks.

Case 3. Born 1889. The first Adams-Stokes attacks appeared in 1957. The frequency of attacks sometimes increased to two or three a day. No signs of cardiac decompensation appeared. In 1961 because of the frequency of attacks a Chardack pacemaker was implanted. The operation was uneventful and he has had no further attacks. Before operation he had a sinus rhythm, but an atrial flutter has since appeared and he shows interference between his own pacemaker and the artificial one.

Case 4. Born 1896. In 1948 she developed symptoms of diabetes mellitus and in 1958 insulin treatment was started. In 1958 she also developed a disturbance of the peripheral circulation and two toes were amputated. In March 1962 she suffered from vertigo, nausea, and vomiting, and her electrocardiogram showed complete heart block. Nine days after admission to hospital repeated Adams-Stokes attacks began. External cardiac massage was performed and since the cardiogram showed asystole the heart was artificially stimulated with external electrodes until internal electrodes and a Chardack pacemaker could be implanted. After the operation she had no Adams-Stokes attacks and felt well till five weeks later when pulmonary œdema developed. Following a pleural puncture she developed pulmonary hæmorrhage and died afterwards. A cardiogram two hours before death showed that all ventricular beats were pacemaker induced.

It is noteworthy that after the operation her urine was free from sugar and the blood sugar was lower than earlier despite the operative trauma and withdrawal of insulin. A week later glycosuria gradually developed and the blood sugar level rose. The exact cause of the improvement of her diabetes is unknown but it is probable that the hypophysis was damaged because of the impaired blood circulation during the AdamsStokes attacks.

Case 5. Born 1884. In 1953 he had his first attack of loss of consciousness. On this occasion he probably had a myocardial infarction. In 1957 his electrocardiogram showed a left bundle-branch block and an atrioventricular block of the first degree. He was then admitted to hospital almost every year because of Adams-Stokes attacks, one of which was followed by unconsciousness for several hours. A radiograph showed a slightly enlarged heart. His blood pressure was $220 / 80 \mathrm{~mm}$. $\mathrm{Hg}$ and pulse 32 a minute. On one occasion he had pulmonary œdema which improved after routine therapy. In 1961 because of the severe Adams-Stokes attacks and the low heart frequency, which doubtless contributed to the cardiac decompensation, an Elema artificial pacemaker was implanted. This functioned satisfactorily but the patient died on the eleventh day from a pleural haemorrhage. A cardiogram half an hour after "death" showed no signs of ventricular fibrillation.

Case 6. Born 1904. In June 1962 his fainting attacks began. A neurological examination revealed no abnormalities. An electrocardiogram showed an atrioventricular block of the first degree and a right bundle-branch block. Adams-Stokes syndrome was diagnosed. The patient was a bricklayer. He would not stop this kind of job but promised not to work on a higher level than the first floor. On September 6 he had several attacks of loss of consciousness. External cardiac massage was given on five different occasions. The cardiogram showed a complete heart block. The pulse rate varied but was often as low as 10-15 beats a minute. Many Adams-Stokes attacks of rather short duration appeared. Molar lactate, atropine, and adrenaline were given. Intravenous hydrocortisone seemed to have the best effect on the pulse rate. On September 7, 1962 an artificial pacemaker (Chardack type but modified to produce stimuli at a rate of 70 a minute) was implanted with a good result.

Case 7. Born 1889, and known to have hypertension at least since 1952, she developed arrhythmia in 1957, which was treated with digitalis. She has had diabetes mellitus since 1958 treated with carbutamide (Nadisan) (N'-sulfa-nilyl-N²-butyl-carbamide) without the need for insulin. In the beginning of August 1962 several attacks of syncope appeared. The cardiogram showed different types of atrioventricular block. After some days repeated Adams-Stokes attacks appeared with a very slow and irregular heart rate. During these attacks she became dizzy or lost consciousness. At this time the $\mathrm{T}$ waves changed grossly indicating various grades of myocardial damage.

The cardiogram showed a complete heart block. An external pacemaker was used intermittently to combat the bradyarrhythmia. In 1962 a pacemaker (Chardack type) was implanted. The post-operative 
TABLE

Cardiac Catheterization Results in Case 8 at Different Ventricular Rates

\begin{tabular}{|c|c|c|c|c|c|}
\hline & \multicolumn{2}{|c|}{$\begin{array}{c}\text { Ventricular rate } \\
\text { before operation } \\
\text { ( } 27 \text { a minute) }\end{array}$} & \multicolumn{3}{|c|}{$\begin{array}{l}\text { Ventricular rate after operation } \\
\text { (60 a minute) }\end{array}$} \\
\hline & Rest & $\begin{array}{l}8 \text { minutes' } \\
\text { exercise }\end{array}$ & Rest & $\begin{array}{l}8 \text { minutes' } \\
\text { exercise }\end{array}$ & $\begin{array}{l}11 \text { minutes } \\
\text { after exercise }\end{array}$ \\
\hline $\begin{array}{lr}\text { Cardiac output }(1 . / \mathrm{min} .) & \ldots \\
\text { Stroke volume }(\mathrm{ml} . / \mathrm{min} .) & \ldots \\
\text { Arterio-venous difference (vol. } \% \text { ) } \\
\text { Pulse pressure (mm. Hg)... } \\
\text { Mean pressure }(\mathrm{mm} . \mathrm{Hg}) . \\
\mathrm{O}_{2} \text {-consumption (ml./min.) } & \ldots \\
\end{array}$ & $\begin{array}{c}5 \cdot 3 \\
230 \\
4 \cdot 5 \\
143 \\
93 \\
240\end{array}$ & $\begin{array}{c}6 \cdot 4 \\
320 \\
7 \cdot 2 \\
160 \\
82 \\
460\end{array}$ & $\begin{array}{c}4 \cdot 7 \\
78 \\
5 \cdot 1 \\
55 \\
116 \\
240\end{array}$ & $\begin{array}{c}9 \cdot 5 \\
158 \\
6 \cdot 2 \\
90 \\
126 \\
590\end{array}$ & $\begin{array}{c}4 \cdot 0 \\
67 \\
5 \cdot 8 \\
71 \\
103 \\
230\end{array}$ \\
\hline
\end{tabular}

course was uneventful in spite of her comparatively poor condition with renal insufficiency, high blood pressure, and unsatisfactory circulation.

Case 8. Born 1898. In 1960 he suffered from tiredness and dizziness. Atropine had no effect. The electrocardiogram showed a right bundle-branch block and an atrioventricular block of the second degree. A radiograph showed a slightly enlarged heart. After a period with different types of arrhythmias complete heart block developed. The attacks of dizziness disappeared but ventricular extrasystoles appeared with a slowing of the heart rate to $25-30$ a min. Because of this a pacemaker (Chardack type) was implanted. The operation and post-operative course were uneventful.

Before operation the patient was catheterized and the stroke volume was determined at rest and during moderate work. At operation the stimulus rate was set at 60 a minute. Two months after the operation the patient was recatheterized with the pacemaker at 60 a minute. Our aim was to determine the cardiac output with the pacemaker set at 60 and 75 stimuli a minute, respectively, but the pacemaker could not be changed to the higher rate (Table).

Case 9. Born 1886. No cardiac symptoms until October 1962 when he became decompensated with dyspnœa and œdema. He also experienced attacks of dizziness and a tendency to fainting but never lost consciousness. The cardiogram showed complete heart block and bundle-branch block of varying types. The heart was moderately enlarged. After some attacks of unconsciousness it was decided to implant a pacemaker (Chardack type). After operation hypotension developed but disappeared after two days' treatment with vasopressor drugs.

It is of interest that atrial flutter developed about a week after the pacemaker was implanted.

Case 10. Born 1899. In 1952 one Adams-Stokes attack with syncope appeared, followed by multiple attacks of dizziness. An electrocardiogram showed supraventricular beats of different origin. Sometimes a more regular nodal rhythm prevailed. A chest radiogram showed a moderately enlarged heart. The patient was treated with atropine, isuprel, and sodium lactate on different occasions but without effect. Because of the attacks of dizziness and the bradyarrhythmia sometimes with a rate as low as $\mathbf{3 0}$ beats a minute a Chardack pacemaker was implanted. The rate was set at 75 a minute to avoid interference between the artificial pacemaker and the "idiocardiac" one. The operation was uneventful.

We have used two types of pacemaker, one constructed by Elema (Johansson, 1961) and one described by Chardack et al. $(1960,1961)$. They differ among other things in the construction of the electrodes and in the stimulus rate. According to published reports one of the chief problems has been the gradually increasing voltage necessary for an adequate stimulus response. This phenomenon has been thought to be caused by creation of scar tissue around the electrodes, such tissue having less electrical conductivity than normal myocardium. To counteract the development of scar tissue the Elema electrodes with a comparatively large contact surface were constructed. A study was recently published (Albert et al., 1962) suggesting that the increasing resistance is caused by a breakage of the wires leading from the electrodes to the pacemaker. If this can be corroborated then it is possible that the shape of the electrodes will turn out to be of minor importance. 
Another difference between the Elema and the Chardack types is that the rate of stimuli in the first one is about 72 a minute and in the latter 60 a minute. Chardack et al. (1961) believe that rates in excess of 60 a minute are contraindicated because the diastolic filling period will be too short for patients with coronary arterial disease and because the duration of asystole which follows a sudden withdrawal of an electrical pacemaking stimulus increases with increasing rate of the artificial pacemaking. It is debatable if this small change in the duration of diastole at 72 and 60 stimuli a minute is of major importance. In the figure shown by Chardack et al. (1961) the time difference for the period of asystole after a stimulus rate of 60 a minute and 100 a minute is only five seconds. Besides not all the patients using an artificial pacemaker have pronounced coronary artery disease.

Chardack et al. (1961) further hold that patients with low rates can compensate for physical exercise by an increase in stroke volume. We think that it will be easier to tolerate a moderate to heavy physical exercise with heart rates slightly above 70 a minute. Many of these patients are of an age and condition permitting them to return to work.

Another argument against a low stimulus rate might be that in cases where the patient's rhythm is of a higher rate than that of the pacemaker interference between the two rhythms will appear more frequently. This will be especially pronounced at exercise. Furthermore there might be a risk of ventricular fibrillation if the artificial stimulus falls in the vulnerable period in cases of interference between the two pacemaker rhythms. Our aim was to study during prolonged cardiographic recording how the stimuli distribute during the ventricular complex, to study the type of extrasystoles produced during different parts of the ventricular complex, and to examine the possible appearance of prefibrillatory movements when a stimulus falls in the vulnerable period.

\section{METHODS}

Electrocardiograms were recorded on three patients (Cases 3, 4, and 5 above) by a direct-writing Elema Mingograf with a film speed of $25 \mathrm{~mm}$. per second. The recording time was about one and a half hours in each patient. The patients' own "idiocardiac" ventricular complexes and the diastolic period afterwards were divided in time intervals with a duration of $0.04 \mathrm{sec}$. from the beginning of the $Q$ or $R$ wave. The number of pacemaker stimuli falling in the different intervals was counted. When the pacemaker stimulus produced an extrasystole the configuration of this was copied and related to the time interval in which the stimulus appeared.

\section{RESULTS}

The pacemaker stimuli were found to appear asynchronously usually with a slight increase in frequency during the first two $0.04 \mathrm{sec}$. periods to a maximum $0 \cdot 1-0.2 \mathrm{sec}$. after the beginning of the QRS complex. They then declined rapidly in frequency (Fig. 3, 4, and 5).

The ventricular complexes were uniform when the pacemaker stimuli appeared later than the first $0.04 \mathrm{sec}$. period but earlier than the $\mathrm{T}$ wave. When the stimulus appeared during the first $0.04 \mathrm{sec}$. period the ventricular complexes were often deformed. When the pacemaker stimulus appeared at, or after, a certain point on the $T$ wave an extrasystole appeared (Fig. 6). However, in no case were multiple extrasystoles or deformed ventricular complexes seen such as those described by Schwartz, Orloff, and Fox (1949).

\section{Discussion}

Much has been written about the "vulnerable period" during which ventricular fibrillation can be produced. Ferris et al. (1936) showed that with an electric shock of $0.03 \mathrm{sec}$. duration it was possible to produce ventricular fibrillation in sheep only when the shock appeared during the $T$ wave. Wiggers and Wégria (1940) reached similar conclusions in their experiments with dogs. There are also observations in man indicating a sensitive part of the ventricular cycle. Lepeschkin and Rosenbaum (1957) observed that the great majority of ventricular extrasystoles began during the period extending from $0.03 \mathrm{sec}$. after the end of the $T$ wave or the beginning of the $U$ wave, to about 


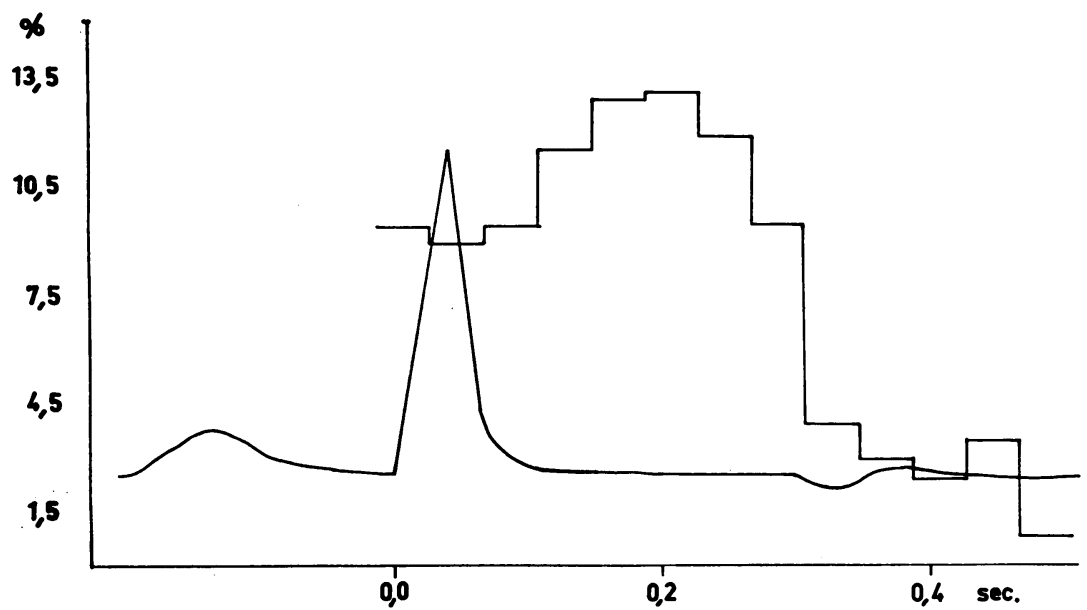

FIG. 3.-Case 4. Percentage artificial pacemaking stimuli (vertical axis) plotted against time intervals of the QRST complex of the spontaneous beats (horizontal axis). The stimuli from the artificial pacemaker appear mainly during the ORS complex and S-T segment of the spontaneous beats. Each short horizontal line had a duration of $0.04 \mathrm{sec}$. and shows what percentage of the total number of artificial stimuli fall during the various time intervals from the beginning of the "idiocardiac" QRS complex (based on 870 observations).

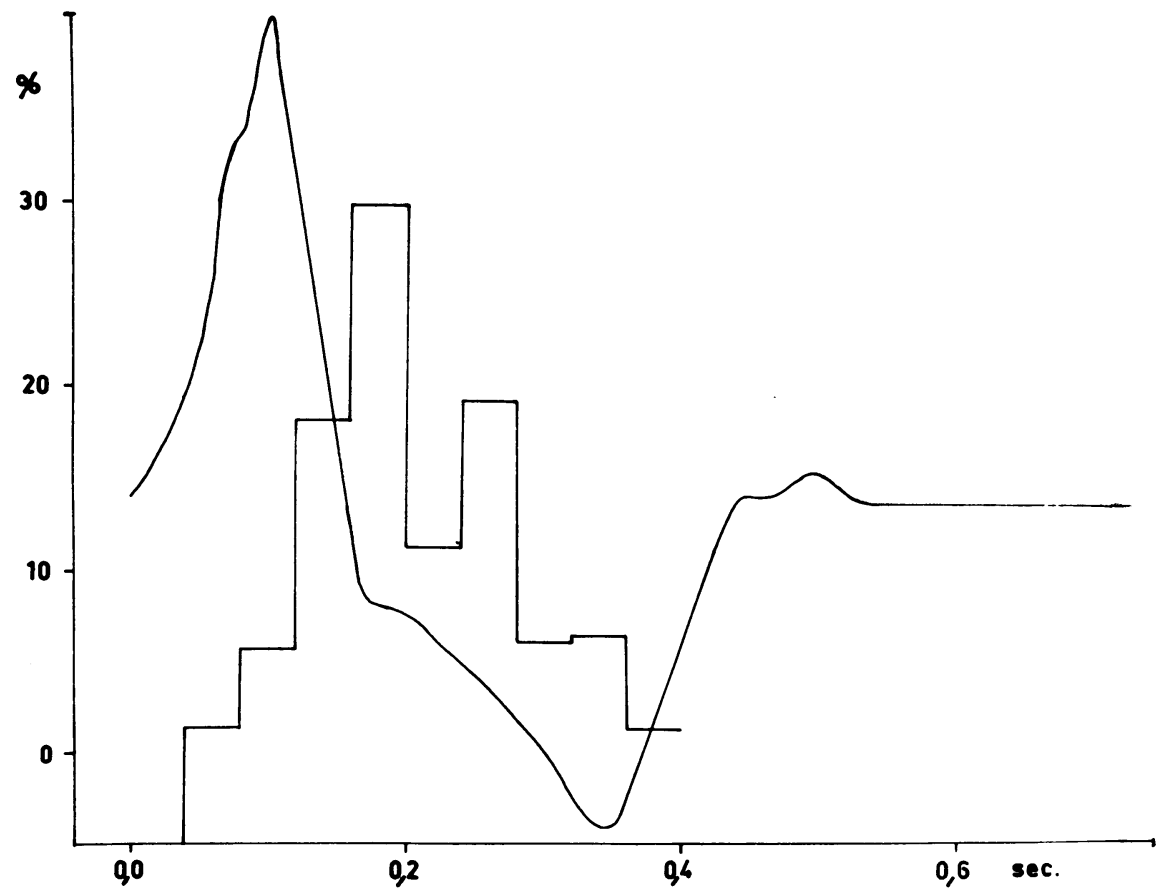

Fig. 4.-Case 5. Based on 1026 observations. Legend as for Fig. 3. 


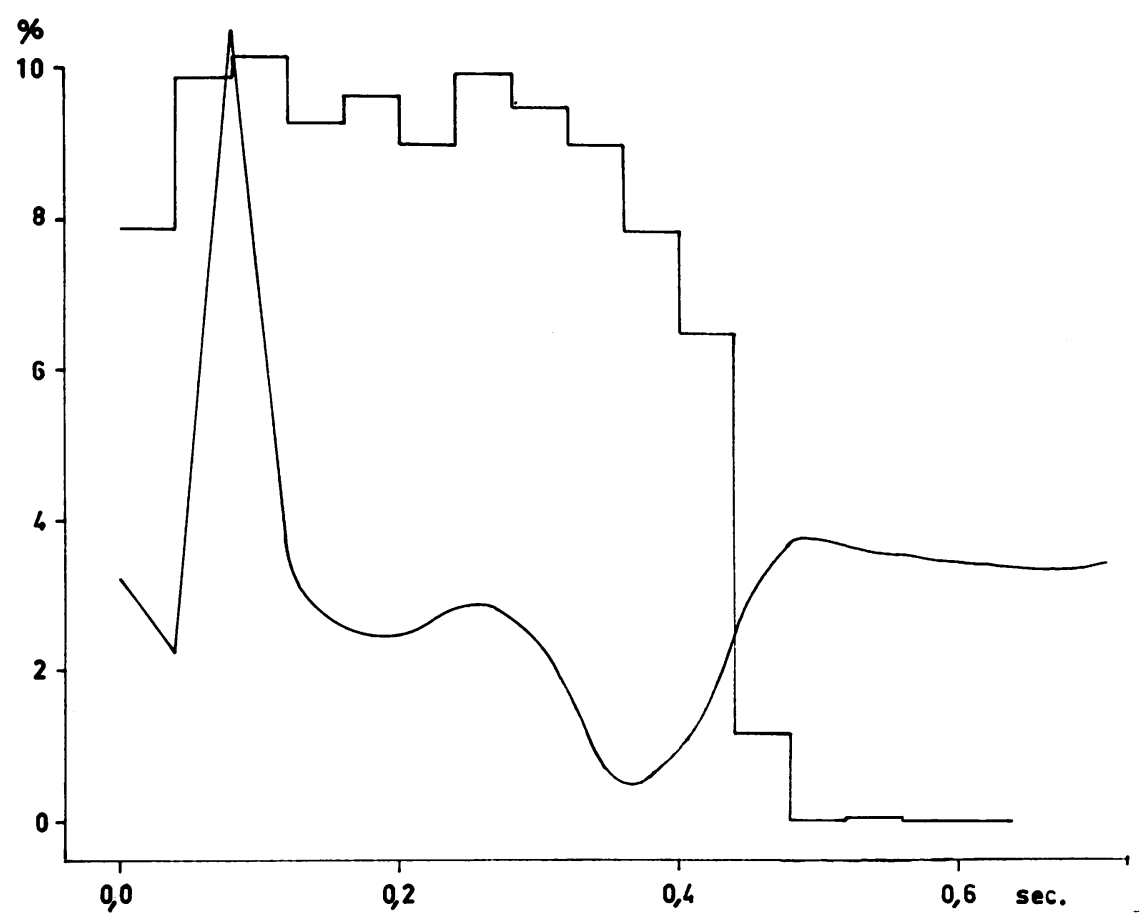

Fig. 5.-Case 3. Based on 4403 observations. Legend as for Fig. 3.
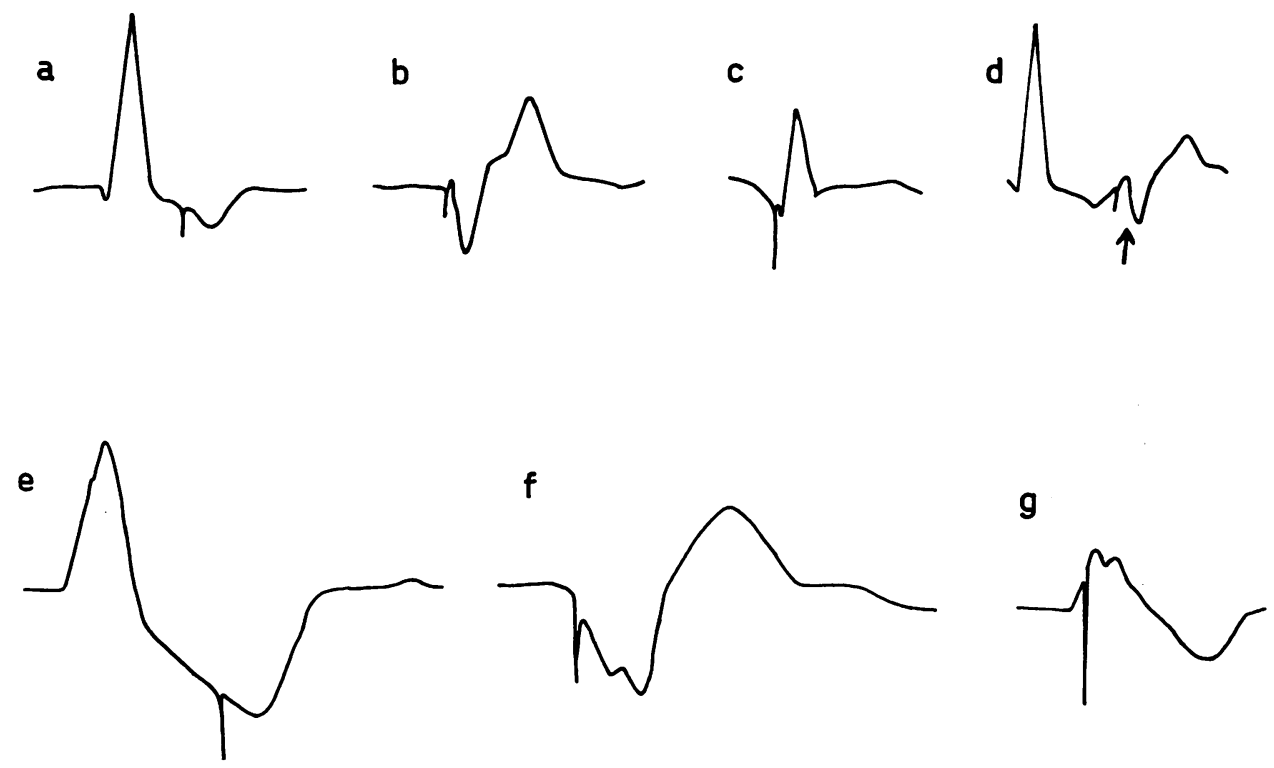

FIG. 6. - Timing of artificial pacemaker artefact in relation to QRST complex. The vertical mark indicates the pacemaker artefact. (a) "Idiocardiac" beat with an artificial stimulus falling in the refractory period (Case 3). (b) Pacemaker induced beat (Case 3). (c) Fusion beat with an almost simultaneous stimulation from the artificial and "idiocardiac" pacemakers (Case 3). (d) The arrow indicates a pacemaker induced beat appearing in the latter part of the $T$ wave (Case 3). (e) "Idiocardiac" beat with pacemaker stimulus falling in the refractory period (Case 5). (f) Pacemaker induced beat (Case 5). (g) Fusion beat with an almost simultaneous stimulation from the artificial and "idiocardiac" pacemakers (Case 5). 
$0.05 \mathrm{sec}$. after the apex of the U wave. Scherf and Schott (1939) from observations on two patients with partial heart block and dropped beats, concluded the existence in man of a supernormal phase of recovery. By premature stimulation of different parts of the ventricular myocardium in isolated perfused guinea-pig hearts, Palmer (1962) studied the mechanism of interruption of the $\mathrm{T}$ wave. He found that ventricular fibrillation was frequently precipitated by interruption of the $T$ wave. Smirk (1949) reported some patients in whom $R$ waves interrupted $T$ waves. He suggested that this finding worsened the prognosis in patients with myocardial disease, partly because in such patients there had been instances of sudden death, probably produced by ventricular flutter or fibrillation.

Thus certain facts indicate that direct stimulation of the myocardium is not without risk, as is the case in patients with artificial pacemakers. This problem has been discussed by Zoll and Linenthal (1960) who thought that although the risk of fibrillation did not appear to be great it could not be definitively assessed. On the other hand Dittmar et al. (1962) are more cautious and think it possible that the sudden death of one of their patients was caused by a ventricular fibrillation due to the artificial pacemaker: they stated also that when the pacemaker stimulus appeared in the $T$ wave multiple ventricular extrasystoles were sometimes seen. The results in the present paper agree with Zoll and Linenthal (1960). There were reasonable anatomical explanations for our two cases that died. Both these (Cases 4 and 5) are included in the long-term electrocardiogram studies described above and in no case did multiple extrasystoles appear when the pacemaker stimulus fell in the $\mathrm{T}$ wave.

The placing of electrodes on the heart has seldom been discussed in earlier papers. In this connexion it is of interest that vanTyn and MacLean (1961) found a significantly higher ventricular fibrillation threshold at the base than at the apex of the left ventricle. The most physiological approach, however, should be with the electrodes at the apex of the ventricle. The apex is preferable since the contraction will begin here and move towards the base, the aorta, and the pulmonary artery. If the electrodes are placed at the base the contraction wave will move towards the apex and produce an insufficient result. This agrees with an observation by Corday (1959) who found that the blood pressure was much lower if a ventricular tachycardia originated at the base than if it originated at the apex.

Through a needle in the brachial artery the blood pressure curve was registered simultaneously with the electrocardiogram in six of the patients. It was apparent that when a $\mathbf{P}$ wave closely preceded the ventricular complex, the pressure peak was higher than when the $P$ wave fell in the ventricular complex, indicating that atrial contraction is of value for the diastolic filling of the ventricle. Fig. 7 shows how the pulse pressure is dependent on the distance between the $P$ wave and the pacemaker stimulus. Curves of the same type were obtained for the systolic and the diastolic pressures. Fig. 7 refers to Case 2 but similar results were obtained from the other patients except those with an atrial flutter.

The artificially produced pressure peaks, at their best, reached the same level as peaks produced by single spontaneous beats, indicating that the artificial pacemaker is effective in spite of the aberrant conduction pathway.

The stimulus rate of artificial pacemakers differs between models. Many authors prefer a frequency of about 70 a minute. Arguments against too low a frequency have been presented earlier in this paper. An important prerequisite here is the determination of the stroke volume and cardiac output at rest and during exercise with different stimulus rates.

Our experience is not great but as we think it of value to collect as much data of this kind as possible we have reported the catheterization findings in Case 8 in detail in the Table. It is apparent that during the same exercise this patient could increase his cardiac output to a much higher level with a heart rate of 60 a minute than with 27 a minute. The percentage increase in stroke volume was less at the lower rate indicating that he used a great part of his reserve capacity also at rest, while the arterio-venous difference was higher during exercise at the low heart rate. This observation indicates that it might be rewarding to study the metabolism in patients with a low heart rate caused by conditions such as complete heart block. It is possible that these patients might develop 


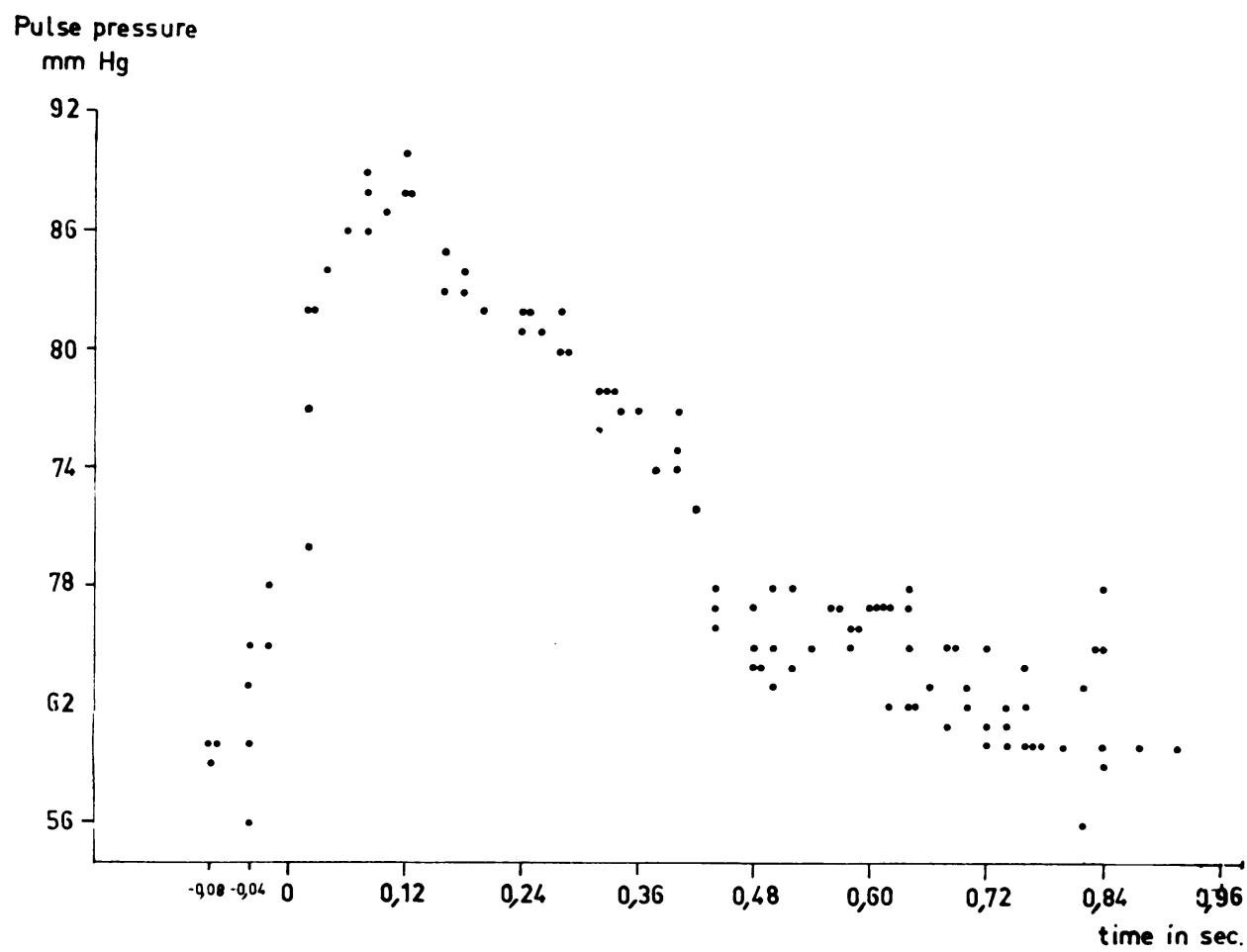

FIG. 7.-(Case 2). The pulse pressure (vertical axis) plotted against the interval between the peak of the $\mathbf{P}$ wave and the pacemaker stimulus (horizontal axis). It is apparent that the pulse pressure is much more satisfactory when the $\mathbf{P}$ wave appears just before the pacemaker stimulus than when it appears a long time before the stimulus.

new pathways for anærobic metabolism. The values from the Table indicate that there is a correlation between the pulse pressure and the stroke volume and from the pulse pressure it would be possible to get a rough estimation of the stroke volume during physical exercise. Calculation of the area covered by the pulse wave might give a still better correlation with the stroke volume. However, the best estimation of the stroke volume, including its rapid changes, would be given by the differential pressure technique as described by Porjé and Rudewald (Rudewald, 1962).

Different hypotheses may be involved in trying to explain why so few pacemaker stimuli appeared during the end of the $\mathrm{T}$ wave and during diastole. The most probable explanation is that the artificially induced beat depolarizes both the myocardial muscle and the conductive system. It would thus be necessary for the "idiocardiac" pacemaker to begin a new repolarization cycle which continues gradually during diastole till a certain membrane potential is reached when depolarization occurs initiating a myocardial contraction. This hypothesis is supported by the fact that most spontaneous beats occurring after a pacemaker-induced beat appear in late diastole. To avoid interference phenomena the rate of the artificial pacemaker should be high enough to suppress the "idiocardiac" pacemaker.

It is worth noting that the atria beat independently of the artificially induced ventricular complexes indicating that there is no retrograde propagation through the atrioventricular node.

\section{SUMMARY}

Ten patients with Adams-Stokes attacks have been treated with artificial pacemakers. Two patients died but there is no reason to suppose that death was caused by ventricular fibrillation 
produced by the pacemaker. The other patients are in good condition but there is pronounced interference in one patient with a high rate in his "idiocardiac" pacemaker and a low rate in his artificial one.

The artificial pacemaker stimuli appeared during the systole of spontaneous beats, very few appearing during the last part of the $\mathrm{T}$ wave or during diastole.

The reasons for different pacemaker stimulus rates are discussed and it appears that a rate of about $70-75$ a minute is preferable to lower rates.

It is thought that the electrodes are best placed near the apex of the left ventricle to produce the most effective contraction from the apex towards the base.

Brachial artery pressure curves from patients with interference between the pacemaker rhythm and the "idiocardiac" rhythm revealed that pacemaker-induced beats preceded by $P$ waves produced systolic peaks as high as the spontaneous beats. When the $\mathbf{P}$ waves fell in the ventricular complex of a pacemaker-induced beat or appeared after it, the systolic pressure peaks were satisfactory but not as high as when the $\mathbf{P}$ waves preceded the ventricular complex.

Hæmodynamic studies in one patient showed that on effort the increase in cardiac output was greater, and the arterio-venous oxygen difference was less, at a heart rate of 60 a minute than at a rate of 27 a minute.

\section{REFERENCES}

Albert, H. M., Glass, B. A., Andonie, J. A., and Cranor, K. C. (1962). Pacemaker failure in complete heart block. Circulat. Res., 10, 295.

Castberg, Th., Jarlov, A., and Rasmussen, K. N. (1962). Komplet atrioventrikulaert block behandlet med intern "pace-maker". Ugeskr. Lag., 124, 385.

Chardack, W. M., Gage, A. A., and Greatbatch, W. (1960). A transistorized, self-contained implantable pacemaker for the long-term correction of complete heart block. Surgery, 48, 643 .

,-- , and - (1961). Correction of complete heart block by a self-contained and subcutaneously implanted pacemaker. J. thorac. cardiovasc. Surg., 42, 814.

Corday, E. (1959). Physiological rationale for the use of vasopressor drugs in the treatment of cardiac arrhythmias. Paper read at the Silver University Meeting of the American College of Chest Physicians, Atlantic City, June 3-7, 1959.

Dittmar, H. A., Friese, G., and Holder, E. (1962). Erfahrungen über die langfristige elektrische Reizung des menschlichen Herzens. Z Z. Kreisl.-Forsch., 51, 66.

Escher, D. J. W., Schwedel, J. B., Eisenberg, R., Gitsios, C., Perna, N., and Jamshidi, A. (1961). Cardiovascular dynamic responses to artificial pacing of patients in heart block. Circulation, 24, 928.

Ferris, L. P., King, B. G., Spence, P. W., and Williams, H. B. (1936). Effect of electric shock on the heart. Elect. Engng $(N . Y$.), 55, 498.

Holswade, G. R., and Linardos, C. (1961). Induction pacemaker for complete heart block. Circulation, $24,958$.

Johansson, B. W. (1960). A case of Adams-Stokes attacks disappearing after cholecystectomy. Acta med. scand., $168,219$.

(1961). Adams-Stokes syndrome. A review and follow-up study of 42 cases. Amer. J. Cardiol., 8, 76.

- (1962). Yttrehjärtmassage. Synpunkter baserade på erfarenheter av ett Malmömaterial. Paper read at Svenska Läkarsällskapet's Meeting, Stockholm, May 29, 1962.

—, Sievers, J., Svanberg, L., Bjerre, I., Cronberg, S., Eriksson, S., Lindh, J., Månsson, T., Wollheim, F., and Zettervall, O. (1962). Yttre hjärtmassage. Svenska Läk.-Tidn., 59, 1285.

Lepeschkin, E., and Rosenbaum, M. B. (1957). XI. Coupling intervals of ventricular extrasystoles in relation to the heart rate, the $U$ wave, and the supernormal phase of excitability. Circulation, 15, 82.

Meier-Sydow, J., Hauch, H-J., Bergmeyer, H. M., and Hüsselmann, H. (1961). Erste Erfahrungen mit einem tragbaren elektrischen Schrittmacher bei postmyokarditischem Herzblock. Med. Welt (Berl.), 1, 583.

Müller, O. F., and Bellet, S. (1961). Treatment of intractable heart failure in the presence of complete atrioventricular heart block by the use of the internal cardiac pacemaker: report of two cases. New Engl. J. Med., 265, 768.

Rudewald, B. (1962). Hemodynamics of the human ascending aorta as studied by means of a differential pressure technique. Acta physiol. scand., 54, suppl. 187.

Palmer, D. G. (1962). Interruption of $T$ waves by premature QRS complexes and the relationship of this phenomenon to ventricular fibrillation. Amer. Heart J., 63, 367.

Scherf, D., and Schott, A. (1939). The supernormal phase of recovery in man. Amer. Heart J., 17, 357.

Schwartz, S. P., Orloff, J., and Fox, C. (1949). Transient ventricular fibrillation. 1. The prefibrillary period during established auriculoventricular dissociation with a note on the phonocardiograms obtained at such times. Amer. Heart J., 37, 21. 
Smirk, F. H. (1949). $\mathrm{R}$ waves interrupting T waves. Brit. Heart J., 11, 23.

vanTyn, R. A., and MacLean, L. D. (1961). Ventricular fibrillation threshold. Amer. J. Physiol., $201,457$.

Wiggers, C. J., and Wégria, R. (1940). Ventricular fibrillation due to single, localized induction and condenser shocks applied during the vulnerable phase of ventricular systole. Amer.J. Physiol., 128, 500.

Zoll, P. M., Frank, H. A., Zarsky, L. R. N., Linenthal, A. J., and Belgard, A. H. (1961). Long-term electric stimulation of the heart for Stokes-Adams disease. Ann. Surg., 154, 330.

, and Linenthal, A. J. (1960). Long-term electric pacemakers for Stokes-Adams disease. Circulation, 22, 341 . 